\title{
KEARIFAN LOKAL DALAM TOPONIMI DI KABUPATEN PANDEGLANG PROVINSI BANTEN: SEBUAH PENELITIAN ANTROPOLINGUISTIK
}

\author{
Asep Muhyidin \\ Universitas Sultan Ageng Tirtayasa \\ Email: muhyidin21@gmail.com \\ D OI: http:/ / dx.doi.org/ 10.17509/ bs jpbsp.v17i2.9661
}

\begin{abstract}
Abstrak
Bahasa dan budaya merupakan dua sisi mata uang yang berbeda, tetapi tidak dapat dipisahkan, karena bahasa merupakan cermin budaya dan identitas diri penuturnya. Toponim dapat digunakan untuk mempelajari aspek budaya setempat sehingga sangat diperlukan untuk melestarikan warisan budaya bangsa. Bahasa yang digunakan dalam penamaan geografis menunjukkan kekayaan budaya suatu bangsa. Penelitian ini bertujuan untuk mendeskripsikan toponimi di Kabupaten Pandeglang yang menggunakan mofem Ci- (Bahasa Sunda), lema kadu (Bahasa Sunda), dan lema pasir (Bahasa Sunda). Penelitian ini menggunakan metode deskriptif analitis. D ata yang digunakan dalam tulisan ini berasal dari sumber data tertulis dan sumber data lisan. Berdasarkan hasil penelitian ditemukan toponim di Kabupaten Pandeglang yaitu: 1) menggunakan morfem d- (BI: air); menggunakan lema kadu(BI: buah durian); dan menggunakan lema pasir (BI: bukit); dan 2) faktor penamaan tersebut berkaitan dengan kondisi geografis dan sosial budaya masyarakat setempat.
\end{abstract}

Kata kunci: toponimi; penelitian deskripstif analitis; Kabupaten Pandeglang

\section{LOCAL VALUES IN THE TOPONYMY OF PANDEGLANG DISTRICT BANTEN PROVINCE: AN ANTROPOLINGUISTIC STUDY}

\begin{abstract}
Language and culture are two sides of a coin; they are inseparable because language is a reflection of the culture and identity of its speaker. Toponyms can be used to study various aspects of the local culture and can help to preserve the nation's cultural heritage. The language used in geographical naming shows the cultural richness of a nation. This study aims to describe the toponymy existing in Pandeglang District, focusing on the morpheme Ci- (Sundanese), kadu entry (Sundanese), and hill entry (Sundanese). This research uses analytical descriptive method. The data used in this paper comes from written as well as oral data sources. The findings revealed that the dominant toponyms in Pandeglang District are as follows: 1) using the morpheme d- (BI: air); using the entry kadu(BI: durian); and using the entry hill (BI: bukit); 2) the naming factor is related to the geographical and sociocultural conditions of the local community.
\end{abstract}

Keywords: toponymy; analytical descriptive method; Pandeglang D istrict 


\section{PENDAH ULUAN}

Bahasa dan budaya merupakan dua sisi mata uang yang berbeda, tetapi tidak dapat dipisahkan, karena bahasa merupakan cermin budaya dan identitas diri penuturnya. Pada tahun 60-an komite Amerika mengenai bahasa dan budaya mengungkapkan hubungan antara bahasa dan budaya. Menurut Bishop (Tarigan, 1991, p. 12) bahwa bahasa tidak bisa dilepaskan dari budaya karena bahasa sebagai subsistem komunikasi adalah suatu bagian dari sistem kebudayaan, bahkan merupakan bagian terpenting dari kebudayaan. Mengenai kaitan antara bahasa dan budaya, Kramsch (2001,p.72) mengelompokkan ke dalam tiga hal yaitu: 1) bahasa mengekspresikan realitas budaya; 2) bahasa merupakan bagian dari realitas budaya; dan 3) bahasa melambangkan realitas budaya.

Toponim dapat digunakan untuk mempelajari aspek budaya setempat sehingga sangat diperlukan untuk melestarikan warisan budaya bangsa. Bahasa yang digunakan dalam penamaan geografis menunjukkan kekayaan budaya suatu bangsa. Dari segi bahasa, penamaan suatu daerah itu bersifat arbitrer, tetapi walaupun manasuka selalu ada makna dibalik nama tempat tersebut. Di dalam sistem toponimi tersebut terdapat nilai-nilai kehidupan atau filosofis yang menjadi ciri khas bahasa dan masyarakat daerah.

Penamaan tempat di Pandeglang tidak pernah terlepas dari berbagai aspek atau berbagai fenomena geografi yang hadir di balik nama tempat tersebut, karena pemberian nama tempat itu tentunya berdasarkan pengalaman dan pertimbangan dari manusia itu sendiri. Ada dua pengalaman yang dipertimbangkan untuk nama tempat itu. Pertama, pertimbangan yang dihasilkan oleh proses-proses alam dan nama dari hasil rekayasa manusia. Kedua, pemberian nama tempat mungkin didasarkan pada gagasan, harapan, cita-cita, dan citra rasa manusia terhadap tempat tersebut agar sesuai dengan apa yang dikehendakinya
Nama merupakan sebuah simbol dari sebuah kebudayaan (Prihadi, 2015) .Nama merupakan kata yang menjadi label bagi setiap makhluk, benda, aktivitas, dan peristiwa di dunia ini dan nama muncul dalam kehidupan manusia yang kompleks dan beragam.Ketika seorang anak manusia lahir, hal yang pertama diberikan ialah nama diri (antroponim) karena dengan nama itu mulailah terbangun suatu jaringan komunikasi antara sang anak dengan dunia luar. Ketika manusia mendiami suatu wilayah, mereka cenderung memberi nama pada semua unsur geografi, seperti nama sungai, gunung, lembah, pulau, teluk, atau selat yang berada di wilayahnya. Bahkan, manusia juga cenderung memberi nama pada daerah yang ditempatinya, seperti nama permukiman, nama desa, nama kampung, nama hutan, sampai nama kota. Tujuan pemberian nama pada unsur geografis itu ialah untuk diidentifikasi, dijadikan patokan, atau dijadikan sebagai sarana komunikasi antarsesama manusia.

Dengan bergesernya nilai-nilai kehidupan dan kebudayaan masyarakat Banten umumnya khususnya di kabupaten Pandeglang, perlu adanya upaya agar pergeseran tersebut tidak lantas mematikan kehidupan budaya masyarakat. Nilai-nilai yang dijunjung tinggi dalam pemakaian bahasa daerah, misalnya, dalam penamaan (toponimi) tradisional tempat oleh masyarakatnya, tergeser oleh istilah modern. Tidak sedikit tempat keramaian maupun permukiman di Pandeglang diberi nama dengan menggunakan istilah asing, misalnya Pantos (Pandeglang Town Square), Gunung Karang Toun Hause Cluster PalmOneresidenee, Perum Saruni Indah Residnee Perum Kadupingan Villace, dll.

Nama geografis adalah nama yang diterapkan pada unsur geografi. Pada umumnya nama geografis adalah nama diri (proper name) atau nama spesifik atau ekspresi di mana suatu entitas dikenal. Entitas (enity) atau maujud geografis adalah semua unsur yang relatif permanen dari bentang alam yang alami maupun bentang alam buatan, termasuk bentang alam lautan, yang mempunyai entitas yang dikenal dalam 
konteks kebudayaan tertentu. Dengan demikian, nama geografis dapat mengacu pada setiap tempat atau unsur atau area di atas muka bumi atau pada kelompok terkait tempat, unsur atau area yang serupa.

Pengungkapan toponim di Kabupaten Pandeglang merupakan salah satu upaya untuk melestarikan kearifan lokal yang ada. Tulisan ini berusaha untuk menyadarkan pada masyarakat betapa pentingnya melakukan penamaan berdasarkan bahasa yang digunakan seharihari oleh masyarakat. Masyarakat jangan sampai dibuat latah dengan menamai suatu tempat dengan istilah asing.

Berdasarkan pendahuluan di atas, masalah dalam penelitian ini dapat dirumuskan dalam pertanyaan sebagai berikut: 1) bagaimanakah penggunaan morfem d-, lema kadu, dan lema pasir dalam toponim di kabupaten Pandeglang?; dan 2) apakah keterkaitan toponim yang diawali morfem d-, lema kadu, dan lema pasir dengan letak geografis dan keadaan sosial budaya di kabupaten Pandeglang?

Ilmu yang mengkaji hubungan antara bahasa dan budaya dinamakan antropologi linguistik yang dipelopori oleh Franz Boas, sedangkan di belahan Eropa dipakai istilah etnolinguistik (D uranti, 1997,p.1-2). Pada dasarnya antropolinguistik, etnolinguistik, dan linguistik budaya secara umum memiliki kesamaan (Duranti, 1997,p.9). Pendekatan antropolinguistik berusaha mencermati apa yang dilakukan orang dengan bahasa dan ujaran-ujaran yang diproduksi, gesture yang dihubungkan dengan konteks pemunculannya. Sibarani (2006,p.12) memerinci hal-hal yang diamati dalam antropolinguistik, yaitu:1) menganalisis istilah-istilah budaya dan ungkapan; 2) menganalisis proses penamaan; 3) menganalisis kesopansantunan; 4) menganalisis konsep budaya dari unsurunsur bahasa; 5) menganalisis etnisitas dari sudut pandang bahasa; dan 6) menganalisis cara berpikir melalui strukur bahasa.

Malinowski dalam Halliday (1978, p.4) mengemukakan bahwa melalui antropolingistik kita dapat menelusuri bagaimana bentuk-bentuk linguistik dipengaruhi oleh aspek budaya, sosial, mental, dan psikologis, apa hakikat sebenamya dari bentuk dan makna serta bagaimana hubungan keduanya. Menurut Boas, bahasa tidak dapat dipisahkan dari fakta sosial budaya masyarakat pendukungnya. Salah satu kontribusi Sapir, dalam Foley (1997,p.49), yang sangat terkenal adalah analisis terhadap kosakata suatu bahasa sangat penting untuk menguak lingkungan fisik dan sosial di mana penutur suatu bahasa bermukim. Pengetahuan mengenai nama lazim disebut onomastika. Ilmu ini dibagi atas dua cabang, yakni pertama, antroponim, yaitu pengetahuan yang mengkaji riwayat atau asal-usul nama orang atau yang diorangkan; kedua, toponimi, yaitu pengetahuan yang mengkaji riwayat atau asal-usul nama tempat (Ayatrohaedi, dalam Rais, 2008,p.53). Disamping sebagai bagian dari onomastika, penamaan tempat atau toponimi juga termasuk ke dalam teori penamaan (naming theory). Nida (1975, dalam Camalia, 2015) menyebutkan bahwa proses penamaan berkaitan dengan acuannya. Penamaan bersifat konvensional dan arbitrer. Dikatakan konvensional karena disusun berdasarkan kebiasaan masyarakat pemakaiannya, sedangkan dikatakan arbriter karena tercipta berdasarkan kemauan masyarakatnya.

Sistem penamaan tempat adalah tata cara atau aturan memberikan nama tempat pada waktu tertentu. Di dalam istilah lain disebut "toponimi". Dilihat dari asal-usul kata atau etimologisnya, kata toponimi berasal dari bahasa Y unani topa ="tempat" dan onoma $=$ "nama". . Jadi, secara harfiah toponimi bermakna "nama tempat". Dalam hal ini, toponimi diartikan sebagai pemberian nama-nama tempat. Dalam kamus Webster's New World Dictionary (1991, p.357) "Toponym (a name of a place) (a name that indicates orign, natural locale ecc" Artinya toponim adalah penamaan tempat yang menunjukkan kealamian suatu lokasi. Kridalaksana (2010, p.170) )menjelaskan bahwa toponim adalah cabang onomastika yang menyelidiki nama tempat. O nomastika 
merupakan penyelidikan tentang asal usul bentuk dan makna, nama diri, terutama nama orang dan tempat.

Toponimi merupakan salah satu cabang ilmu kebumian yang mengkaji dan mempelajaripermasalahan penamaan unsure geografi baik alamimaupun buatan manusia. Selain mempelajari masalah nama, ilmu ini juga mengkaji pembakuan penulisan, ejaanpengucapan (fonetik), sejarah penamaan, serta korelasi nama dengan kondisi alam atau sumber daya yang dimiliki sebuah unsur geografi. Toponim memiliki hubungan erat dengan kondisi fisik geografis, masyarakat yang menghuninya, dan kebudayaan yang tumbuh di wilayah tersebut. Ikhwal nama maknanya sangat luas, tidak hanya secara fisik seperti kondisi lokasi geografisnya saja, juga meliputi asalusul, kondisi dan social budaya, serta agama masyarakatnya, nilai-nilai yang terkandung di dalam system kebudayaan yang dimiliki secara sosial itu akan tampak dalam wujud symbol pemberian nama dan perilaku suatu masyarakat (Kosasih, 2010, p. 34).

Menurut Sudaryat (2009, dalam Kosasih, 2010) penamaan tempat atau toponimi memiliki tiga aspek, yaitu 1) aspek perwujudan; 2) aspek kemasyarakatan; dan 3) aspek kebudayaan. Ketiga aspek tersebut sangat berpengaruh terhadap cara penamaan tempat dalam kehidupan masyarakat. Aspek wujudiah atau perwujudan (fisikal) berkaitan dengan kehidupan manusia yang cenderung menyatu dengan bumi sebagai tempat berpijak dan lingkungan alam sebagai tempat hidupnya (Sudaryat, 2009, dalam Kosasih, 2010). Dalam kaitannya dengan penamaan kampung, masyarakat memberi nama kampung berdasarkan aspek lingkungan alam yang dapat dilihat. Sudaryat membagi lingkungan alam tersebut ke dalam tiga kelompok, yaitu (1) latar perarian (hidrologis); (2) latar rupabumi (geomorfologis); (3) latar lingkungan alam (biologis-ekologis).

Ruspandi dan Mulyadi (2014) berdasarkan penelitian yang telah dilakukan tentang toponimi di Kota Cirebon menemukan bahwa secara garis besar toponimi di Kota Cirebon dilatarbelakangi aspek fisikal, aspek sosial, dan aspek cultural. Aspek fisikal meliputi: a) unsur biologis; b) unsur hidrologis; dan c) unsur geomorfologis. Aspek sosial meliputi: a) tempat spesifik; b) aktivitas masa lampau; c) harapan; d) nama bangunan bersejarah;dan e) nama tokoh Aspek kultural yaitu legenda/ cerita rakyat.

Dalam penelitiannya tentang toponimi Lamongan, Camalia (2015) menyimpulkan bahwa toponimi di Kota Lamongan sangat berkaitan dengan sosok yang bernama Hadi, murid Sunan Giri yang ditugaskan untuk membimbing dan memimpin masyarakat Lamongan. Sebagai bentuk apresiasi dan penghormatan terhadap jasa Hadi, maka wilayah kepemimpinan Hadi ini disebut sebagai Lamongan. Berdasarkan analisis dari segi semiotik, Lamongan merupakan jenis tanda indeks yang tersusun atas sistem penanda dan petanda yang saling terkait bagaian dua sisi mata uang yang tidak dapat dipisahkan. Keterkaitan antara pikiran masyarakat untuk menjaga hubungan baik dengan sesama manusia, budaya Jawa untuk senantiasa berlaku hormat, dan penggunaan bahasa yang teraealisasi dengan penggunaan bahasa Kawi dalam toponimi Lamongan memperkuat Hipotesis Sapir-Whorf.

Saerheim (2014) dalam penelitiannya di Norwegia menyimpulkan bahwa penamaan tempat disesuaikan dengan tradisi bodaya lokal setempat. Penamaan berdasarkan tradisi lisan dari mitos cerita rakyat yang sudah secara turun temurun diwariskan nenek moyang. Tradisi lisan tersebut sudah beabad-abad keberadaannya.

Kajian Toponimi yang dikaitkan dengan hipotesis Sapir-Worf pernah dilakukan oleh Mardiana (2014). Dalam penelitiannya tersebut Mardiana mengkaji penamaan tempat yang menggunakan bahasa Jawa yang terdapat di Kota Mojokerto. Dalam penelitiannya tersebut ia memperkuat Hipotesis Sapir-Worf yang dimana ia menemukan adanya keterkaitan antara bahasa, budaya, dan pikiran manusia dalam proses penamaan tempat di Kota Mojokerto yang menggunakan bahasa Jawa. Penelitian tersebut menemukan katerkaitan 
antara bahasa, pikiran, dan budaya pada penaamaan tempat-tempat di Mojokerto.

\section{METODE}

Penelitian ini menggunakan metode deskriptif analitis. Penelitian deskriptif analitis adalah suatu bentuk penelitian yang ditujukan untuk mendeskripsikan fenomenafenomena yang ada, baik fenomena alamiah maupun fenomena buatan manusia. Menurut Sukmadinata (2006, p.72) fenomena itu dapat berupa bentuk, aktivitas, karakteristik, perubahan, hubungan, kesamaan dan perbedaan antara fenomena yang satu dengan fenomena yang lainnya. Penelitian deskriptif merupakan penelitian yang brusaha mendeskripsikan dan menginterpretasi sesuatu, misalnya kondisi atau hubungan yang ada, pendapat yang berkembang, prosese yang sedang berlangsung, akibat atau efek yang terjadi, atau tentang kecenderungan yang tengah berlangsung.

Langkah-langkah dalam penelitian ini adalah sebagai berikut. Pertama, melakukan studi pustaka berhubungan dengan teori dan konsep kajian antropolingistik. Kemudian dilanjutkan dengan pengumpulan data dari berbagai sumber baik lisan maupun tulisan berkaitan dengan toponim desa di Kabupaten Pandeglang. Selanjutnya, setelah data terkumpul, penulis mencatat data yang sekiranya diperlukan atau dianggap penting sebagai sumber informasi. Langkah selanjutnya adalah menelaah data, termasuk di dalamnya mereduksi data yang tidak diperlukan. Setelah itu data disusun dan dianalisis. Langkah terakhir adalah membuat simpulan terhadap penelitian tersebut.

D ata yang digunakan dalam tulisan ini berasal dari sumber data tertulis dan sumber data lisan. Data tertulis diperoleh dari buku Kantor Pos dan Giro. Data tulis juga diperoleh dari koran daerah, tabloid, majalah, internet, dan juga monografi Kabupaten Pandeglang yang memuat informasi yang diperlukan. Sumber data tertulis juga digunakan karena beberapa nama telah sering dipublikasikan, terutama nama kecamatan, kelurahan, dan nama kampung. Data lisan tersebut diperoleh dari informan-informan yang mengetahui nama dan maknanya melalui diskusi dan wawancara. 


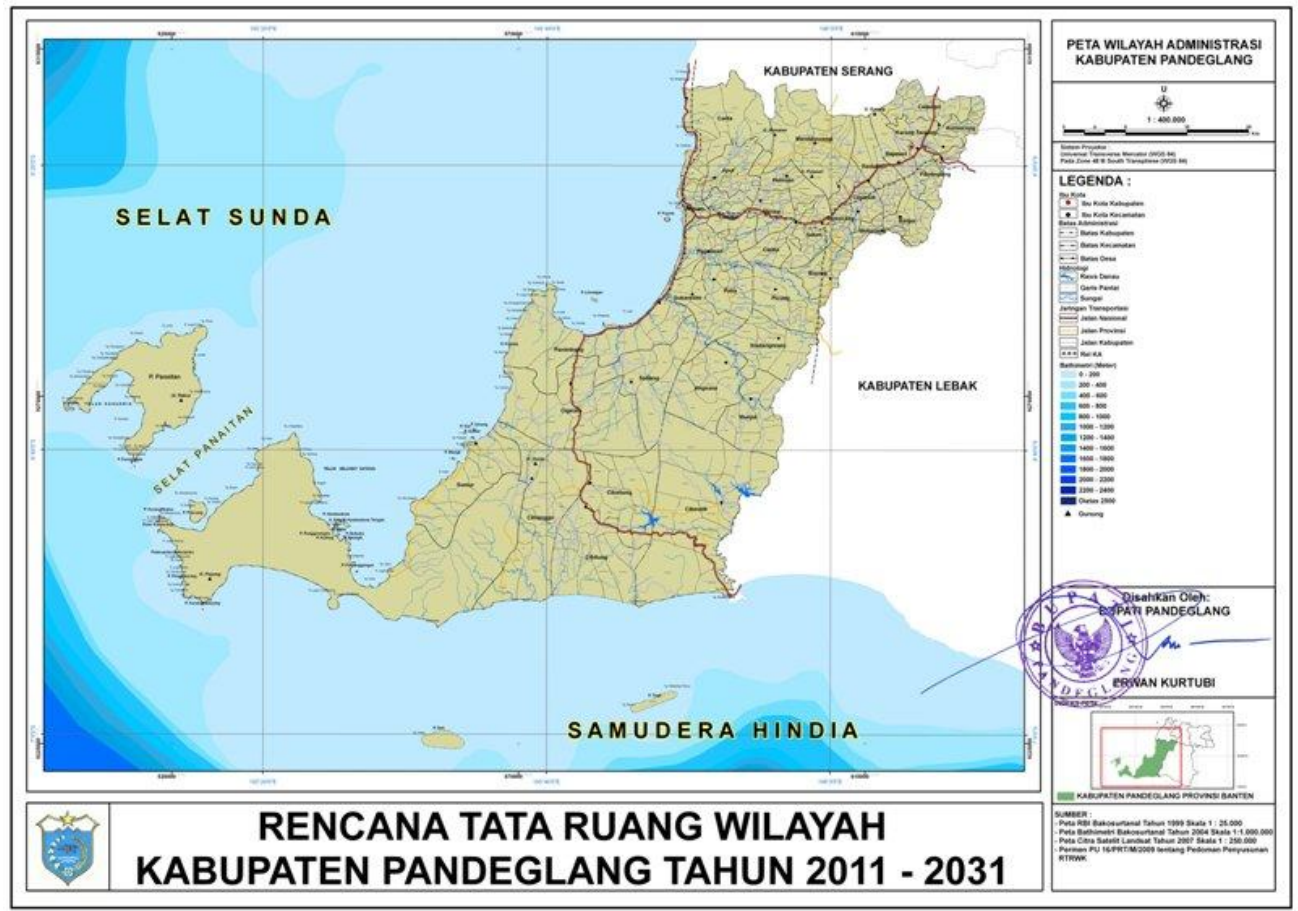

G ambar 1: Peta Kabupaten Padeglang (Sumber: http:/ / pandeglangkab.go.id/ profil.php)

HASIL DAN PEMBAH ASAN

Berdasarkan hasil pengumpulan data, dari 35 nama kecamatan dan 335 nama desa/ kelurahan di kabupaten Padeglang dan berdasarkan hasil wawancara dengan beberapa orang penduduk asli Kabupaten Pandeglang. Penulis menemukan tiga penanda toponim yang dominan yaitu sebagai berikut.

1. Morfem Ci-

a. Morfem Ci- ditambah nama tumbuhan ditemukan pada toponim seperti: (1) Cipinang; (2) Cihanjuang; (3) Cikadu; (4) Ciseureuheun; (5) Cipicung; (6) Cikadongdong; (7) Cimanggu; (8) Cikadueun; (9) Cisereh; (10) Cigadung; (11) Cilaja; (12) Cibitung; (13) Ciawi; (14) Cimanggu (15) Cijambe (16) Cijeruk; (17) Ciinjuk.

b. Mofem Ci- ditambah nama warna ditemukan pada toponim seperti: (1) Cibeureum; (2) Cibodas; (3) Cikoneng; (4) Cikayas; (5) Cibungur; (6) Cihideung.

c. Morfem Ci- ditambah nama keadaan alam yang berhubungan dengan air ditemukan pada toponim seperti: (1) Cikiruh; (2) Cikiruhwetan; (3) Ciburial; (4) Ciherangjaya; (5) Ciherang.

d. Morfem Ci- ditambah penamaan hewan terdapat pada toponim seperti: (1) Cikalong; (2) Cibadak; (3) Cimanuk; (4) Cikuya; (5) Ciodeng; (6) Cipeucang.

e. Morfem Ci- ditambah kata yang berhubungan sifat ditemukan pada toponim seperti: (1) Cimanis; (2) Cigeulis; (3) Cihaseum; (4) Cipait.

f. Morfem Ci- ditambah kata yang berhubungan dengan tempat terdapat pada toponim seperti: (1) Cibaliung; (2) Citalahab; (3) Cijakan;

Citumenggung; (5) Cikentrung; (6) Cinoyong; (7) Citeluk; (8) Cibingbin; (9) Cijaralang; (10) Cibarani; (11) Citaman; (12) Cigondang; (13) Cikentrung; (14) Cilabanbulan; (15) Cililitan; (16) Cilentung; (17) Ciandur.

g. Morfem Ci- ditambah kata yang berhubungan verba ditemukan pada toponim seperti: (1) Cigandeng; (2) Citeureup; (3) Cimoyan.

2. Lema Kadu 
a. Lema Kadu ditambah dengan nama hewan ditemukan pada toponim seperti: (1) kadubadak; (2) Kaduengang; (3) Kadumerak; (4) Kadugajah; (5) Kadubanen; (6) Kadumaung; (7) Kadubangkong.

b. Lema Kadu ditambah dengan nama tumbuhan ditemukan pada toponim seperti: (1) Kadulimus; (2) Kadumalati; (3) Kadukacapi; (4) Kadugadung.

c. Lema Kadu ditambah dengan nama warna ditemukan pada toponim seperti: (1) Kadubelang; (2) Kaduhejo; (3) Kadugading; (4) Kaducoklat; (5) Kadubeureum.

d. Lema Kadu ditambah dengan nama peralatan rumah tangga ditemukan pada toponim seperti: (1) Kadulisung; (2) Kadupayung.

e. Lema Kadu ditambah dengan nama tempat ditemukan pada toponim seperti: (1) Kaduela; (2) Kadubale; (3) Kadumadang; (4) Kaduronyok; (5) Kadugemblo;

(6) Kadubera;

Kadudampit.

f. Lema Kadu ditambah dengan keadaan alam ditemukan pada toponim seperti: (1) Kaducaang; (2) Kadubungbang; (3) Kadujangkung.

3. Lema Pasir

a. Lema Pasir ditambah dengan nama keadaan alam ditemukan pada toponim seperti: (1) Pasirkarang; Pasirpanjang; (3) Pasirsedang.

b. Lema Pasir ditambah dengan nama tumbuhan ditemukan pada toponim seperti: (1) Pasirawi; (2) Pasirpeuteuy; (3) Pasireurih; (4) Pasirgadung; (5) Pasirkadu

c. Lema Pasir ditambah dengan verba ditemukan pada toponim seperti: (1) Pasirtenjo; (2) Pasirlancar.

Berdasarkan data dari situs pemerintah Kabupaten Pandeglang http:/ / www.pandeglangkab.go.id.

Kabupaten Pandeglang berada pada bagian barat daya Propinsi Banten dan secara geografis terletak antara $6^{\circ} 21^{\prime}$ s.d. $7^{\circ} 10^{\prime}$ Lintang Selatan (LS) dan $104^{\circ} 8^{\prime}$ s.d. $106^{\circ} 11^{\prime}$ Bujur Timur ( BT ), dengan batas administrasinya adalah: sebelah utara Kabupaten Serang; sebelah timur Kabupaten Lebak; sebelah selatan Samudera Indonesia; sebelah barat Selat Sunda. Luas wilayah Kabupaten Pandeglang adalah 274.689,91 Ha atau 2.747 $\mathrm{Km}^{2}$ dan secara wilayah kerja administrasi terbagi atas 35 kecamatan, 322 desa dan 13 kelurahan. Dari jumlah tersebut toponim yang paling dominan adalah diawali morfem d-, (BI: air) kemudian lema kadu (BI: durian), dan lema pasir(BI: bukit).

Topografi di Kabupaten Pandeglang sebagian besar merupakan dataran rendah yakni di daerah bagian tengah dan selatan, dengan variasi ketinggian antara 0 - 1.778 meter di atas permukaan laut (dpl) dengan luas sekitar 85,07\% dari luas wilayah kabupaten. D engan topografi sebagian besar daerah rendah, maka toponim pun sebagian besar berkaitan dengan $\dot{\alpha}-$, misalnya daerah Cikayas (BI: merah muda), Cikadu (BI: durian), Cikinuh (BI: keruh), Ciodang (BI: lebah), Cigalis (BI: cantik), Cigandeng (BI: berisik) dll. Hal ini mengingat di Kabupaten Pandeglang mengalir empat belas sungai baik yang besar maupun yang kecil. Keempat belas sungai tersebut adalah Sungai Cidano, Sungai Cibungur, Sungai Cisanggona, Sungai Ciliman, Sungai Cihonje, Sungai Cipunagara, Sungi Cisumur, Sungai Ciseureuhan, Sungai Cijaralang, Sungai Cikadongdong, Sungai Ciseukeut, Sungai Cimara, Sungai Cibaliung, dan Sungai Cicanta.

Toponim berawalan morfem d- yang paling mendominasi adalah yang ditambah nama tumbuhan. Berdasarkan informasi dari sumber data tertulis maupun dari informan, hal ini dikarenakan di daerah tersebut pada zaman dahulu terdapat nama tumbuhan. Misalnya, Cikadu pada zaman dahulu di tempat tersebut banyak ditumbuhi pohon kadu (BI: durian). Sampai saat ini pun di daerah tersebut masih banyak terdapat pohon durian, oleh karena itu Kabupaten Pandeglang terkenal sebagai salah satu penghasil durian di Provinsi Banten.

D aerah pegunungan pada umumnya mempunyai ketinggian $\pm 400 \mathrm{~m} \mathrm{dpl}$, dataran rendah bukan pantai pada umumnya memiliki ketinggian rata-rata $30 \mathrm{~m}$ dpl dan 
daerah dataran rendah pantai pada umumnya mempunyai ketinggian rata-rata 3 $m$ dpl. Kemiringan tanah di Kabupaten Pandeglang bervariasi antara 0 - $45 \%$; dengan alokasi $0-15 \%$ areal pedataran sekitar Pantai Selatan dan pantai Selat Sunda; alokasi 15 - $25 \%$ areal berbukit lokasi tersebar; dan alokasi 25 - $45 \%$ areal bergunung pada bagian Tengah dan Utara. Pandeglang memiliki 6 gunung yaitu : Gunung Karang (1.778 mdpl); Gunung Pulosari (1.346 $\mathrm{mdpl})$; Gunung Aseupan (1.174 mdpl); Gunug Payung (480 mdpl); Gunung Honje (620 mdpl); dan Gunung Tilu (562 mdpl). Topografi daerah pegunungan banyak ditemukan toponim berawalan kata pasir (BI: bukit), misalnya daerah Pasirkadu (BI: durian), Pasirtenjo(BI: lihat), dll.

Toponim tidak hanya sekedar nama yang hanya menunjukkan lokasi saja, tetapi dibalik nama tersebut terkandung budaya setempat. Masyarakat Pandeglang umumnya menggunakan bahasa Sunda sebagai bahasa pengantar sehari-hari. Bahasa tersebut menjadi alat pengungkap budaya yang ada di masyarakat. Toponim diberikan berdasarkan apa yang terjadi di masyarakat. Masyarakat umumnya bekerja sebagai petani yang setiap hari pergi ke sawah ataupun ke ladang. Toponim yang berkaitan dengan hasil pertanian misalnya Pasirpatery (BI: petai), Pasirgadung(BI: semacam ubi), dll.

Aktivitas pertanian di Kabupaten Pandeglang menghasilkan beberapa komoditas. Buah durian merupakan salah satu komoditas yang paling utama. Di sepanjang perjalanan antara Serang ke Pandeglang banyak ditemukan pedagang buah durian, baik pedagang kaki lima maupun pedagang yang terintegrasi dengan manajemen yang baik. Salah satu pedagang durian yang sukses adalah $\mathrm{H}$. Arif. Beliau terkenal dengan nama "D urian Jatohan $\mathrm{H}$. Arif". Toponim yang berkaitan dengan buah durian cukup banyak ditemukan diantaranya Kadubadak, Kadumalati (BI: bunga melati), Kadu higo (BI: hijau), Kadu lisung (BI: lesung), dan lain-lain.

Kabupaten Pandeglang memiliki jenis hewan yang beragam. Hewan yang paling dilindungi adalah badak bercula satu (Rhinoctos Sondaias). Hewan ini keberadaannya hampir punah dan hanya ada di daerah Ujung Kulon. Keberadaan badak di Pandeglang terlihat dari toponim yang ada misalnya Cibadak, Kadubadak.

Toponim khas di Kabupaten Pandeglang yang unik dan bernuansa kearifan lokal adalah toponim yang menggunakan nama buah durian (BS: kadu). Kata kadu dapat dipadukan dengan toponim yang berawalan morfen $\dot{\alpha}$ - terdapat pada toponim Cikadu. Begitupun kata kadu ini dapat dipadukan dengan toponim yang berasal dari kata pasir (BI: bukit) terdapat pada toponim Pasirkadu.

\section{SIMPULAN}

Toponim di Kabupaten Pandeglang kini sudah dipengaruhi oleh istilah-istilah asing. Hal ini perlu diwaspadai oleh masyarakat setempat. Penamaan suatu daerah berkaitan antara bahasa dan budayanya. Bahasa sebagai produk budaya tentu merepresentasikan budaya lokal. Oleh karena itu kaitan antara bahasa dan budaya ibarat dua sisi mata uang yang tidak dapat dipisahkan.

Berdasarkan hasil penelitian ditemukan toponim yang dominan di Kabupaten Pandeglang yaitu: 1) menggunakan morfem d- (BI: air); lema kadu (BI: buah durian); dan lema pasir (BI: bukit);dan 2) Secara geografis sebagian besar wilayah Pandeglang adalah dataran rendah yang mengalir banyak sungai sehingga penamaan pun berkaitan dengan air. Selain dataran rendah, di Pandeglang pun terdapat dataran tinggi berupa beberapa gunung. $\mathrm{Hal}$ ini terlihat dari toponim yang menggunakan kata pasir. Umumnya masyarakat Pandeglang memiliki mata pencaharian sebagai petani, baik petani di sawah maupun di ladang. Sebagai daerah agraris, Pandeglang terkenal memiliki beberapa komoditas unggulan hasil pertanian. Salah satunya adalah buah durian yang terkenal sebagai "raja buah". D alam hal ini toponim di Pandeglang pun banyak yang menggunakan kata durian (BS: kadu). 


\section{DAFTAR RUJUKAN}

Camalia, M. (2015). Toponimi Kabupaten Lamongan (Kajian Antropologi Linguistik). Parde Jaumal of Linguistics andEducation, 5(1), 74-83.

Duranti, A.(1997). Linguistics Antropology. Cambridge: Cambridge University Press.

Foley, W.A. (1997). Antropdogical lingristics an introduction Oxford: Blackwell Published.

Halliday, M.A.K. (1978). Language and sodal semidics the sodal interprtation of language and meaning London: Edward Arnold.

Kosasih, D. (2010). "Kosmologi sistem nama diri (antroponim) masyarakat sunda". Seminar Intemasional Hari Bahasa Ilau, pp 33-38.

Kramsch, C. (2001). Language and alture Oxford: Oxford University Press.

Kridalaksana, H. (2010). Kams lingiistik. Jakarta: G ramedia Pustaka Utama.

Mardiana, W. (2014). The sapir-whorf hypotesis and toponomy study: place naming using javanese language. Makalah Konferens Linguistik Tahuman Atmajaya.

Rais, J. (2008). Toponimi Indonesia Jakarta: Pradnya Paramita.

Ruspandi, J., \& Mulyadi. (2014). Fenomena geografis di balik makna toponimi di kota Cirebon. Jumal Geografi Gea, 14(2) 1-13.

Saerheim, I. (2014). Place names in oral tradition: sources of local language and cultural history . Procedings of the 25th Intemational Congess of Onmastic Saiences Glasgow 25-29 August 2014. pp 285-292

Prihadi. (2015). The linguistic structure of toponim system of hamlets/villages in Yogyakarta special province (an antropolinguistic study). European Jamal of Engineeing and Techndog;, 1(3), 1-16

Sibarani, R. (2006). "Antropolinguistik dan Semiotika". Dalam Teuku Kemal
Fasya, \& al. (ed.). Kata dan luka kebudayaan Medan: USU Press.

Sukmadinata. (2006). Meode penditian pendidkan Bandung: Remaja Rosdakarya.

Tarigan, H.G. (1991). Metode pengajaran bahasa 1. Bandung: Angkasa.

Webste's NewWordd Dicionary. (1991). New York: Prentice Hall General Reference

http:/ / www.pandeglangkab.go.id 